Proceedings

\title{
Protective Antifungal Activity of Plantago major Extract Against the Phytopathogenic Fungi Phytophthora cinnamomi, Diplodia corticola and Colletotrichum Species ${ }^{+}$
}

\author{
Cláudia Ferreira ${ }^{1}$ and Rui Oliveira ${ }^{1,2,3, *}$ \\ 1 Centre of Molecular and Environmental Biology (CBMA), Department of Biology, Campus de Gualtar, \\ University of Minho, 4710-057 Braga, Portugal; claudiagt916@gmail.com \\ 2 Centre for the Research and Technology of Agro-Environmental and Biological Sciences (CITAB), \\ Department of Biology, Campus de Gualtar, University of Minho, 4710-057 Braga, Portugal \\ 3 Centre of Biological Engineering (CEB), Department of Biology, Campus de Gualtar, University of Minho, \\ 4710-057 Braga, Portugal \\ * Correspondence: ruipso@bio.uminho.pt \\ + Presented at the 1st International Electronic Conference on Food Science and Functional Foods, \\ 10-25 November 2020; Available online: https://foods_2020.sciforum.net/.
}

Citation: Ferreira, C.; Oliveira, R. Protective Antifungal Activity of Plantago major Extract against the Phytopathogenic Fungi Phytophthora cinnamomi, Diplodia corticola and Colletotrichum Species. Proceedings 2021, 70, 94. https://doi.org/10.3390/ foods_2020-07678

Published: 9 November 2020

Publisher's Note: MDPI stays neutral with regard to jurisdictional claims in published maps and institutional affiliations.

Copyright: $(2020$ by the authors. Licensee MDPI, Basel, Switzerland. This article is an open access article distributed under the terms and conditions of the Creative Commons Attribution (CC BY) license (http://creativecommons.org/licenses/by/4.0/).

\begin{abstract}
Synthetic fungicides for crops protection raise environmental and human concerns due to accumulation in edible vegetables, showing significant toxicity to humans, and in soil, groundwater and rivers, affecting ecological balance. In addition, they are prone to the development of resistant strains because of the single target-based mechanism of action. Plant extracts provide attractive alternatives, as they constitute a rich source of biodegradable secondary metabolites, such as phenols, flavonoids and saponins, which have multiple modes of antifungal action and a lower probability of the development of resistant fungi. This work has the objective of identifying plant extracts with antifungal activity, aiming to contribute to food safety and sustainable agricultural practices. We selected a saponin-containing plant, Plantago major, and extracted secondary metabolites with $50 \%$ $(v / v)$ ethanol, dried by evaporation, and dissolved in water. For antifungal activity, the phytopathogenic fungi Colletotrichum acutatum, Colletotrichum gloeosporioides, Colletotrichum godetiae, Colletotrichum nymphaeae, Diplodia corticola and Phytophthora cinnamomi were selected because they affect fruits and vegetables, such as strawberry, almond, apple, avocado, blueberry and chestnut trees. The aqueous extract was incorporated into PDA medium at different concentrations and mycelial discs were placed in the center of each Petri dish. Growth was measured as the radial mycelial growth at 3, 6, and 9 days incubation at $25^{\circ} \mathrm{C}$ in the dark. The maximum growth inhibition (32.2\%) was obtained against P. cinnamomi with $2000 \mu \mathrm{g} / \mathrm{mL}$ extract followed by C. gloeosporioides (25.7\%) on the sixth day and by $C$. godetiae and C. nymphaeae (21.1\%) on the ninth day. Results show that $P$. major presents antifungal activity in all phytopathogenic fungi tested and the extract can be used to protect important crops, by inhibiting the development of fungal infections and promoting food security and a sustainable agriculture.
\end{abstract}

Keywords: antifungal phytochemicals; natural antifungals; sustainable crop production; sustainable agriculture; Plantago major

\section{Introduction}

Crop-protecting synthetic fungicides raise environmental and human concerns due to accumulation in edible vegetables [1], showing significant toxicity to humans [2], and in soil [3], groundwater and rivers [4], affecting ecological balance. Plantago major (Figure 1) extract is a rich source of biodegradable secondary metabolites, which have multiple modes of antifungal action and a lower probability of the development of resistant fungi strains, a very notorious problem with the use of synthetic fungicides [5]. The objective of 
this work is to evaluate the antifungal activity of P. major extract, as a potential replacement of synthetic fungicides, aiming to contribute to sustainable agriculture practices and food safety.

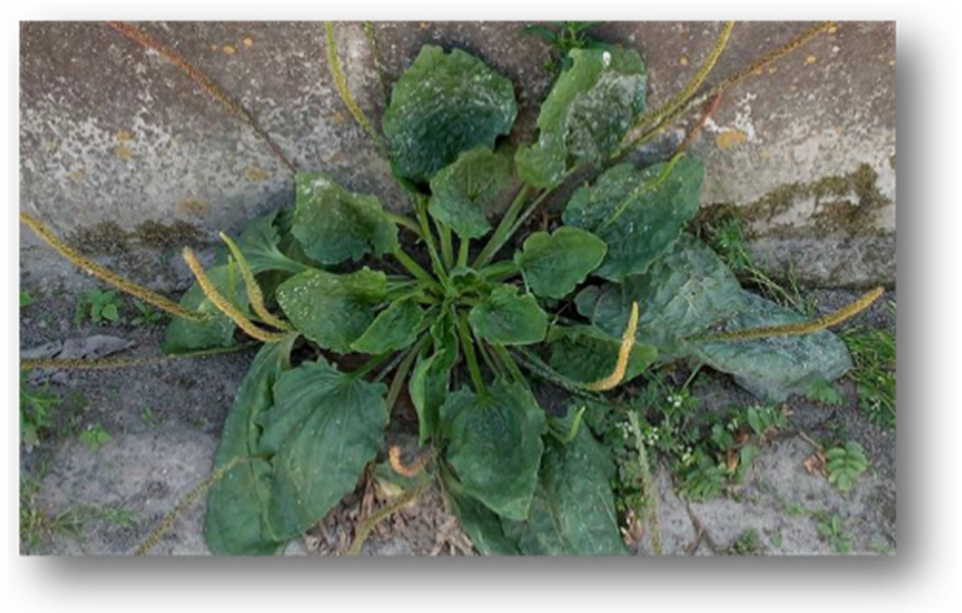

Figure 1. Plantago major.

\section{Material and Methods}

To investigate P. major inhibition on the mycelial growth of the phytopathogenic fungi Colletotrichum acutatum, Colletotrichum gloeosporioides, Colletotrichum godetiae, Colletotrichum nymphaeae, Diplodia corticola and Phytophthora cinnamomi, the dried plant was extracted with $50 \%(v / v)$ ethanol, the solution dried by evaporation, and the residue dissolved in water. The aqueous extract was incorporated into PDA medium at different concentrations, 100, 500, 1000 and $2000 \mu \mathrm{g} / \mathrm{mL}$, and mycelial discs of each fungus were placed in the center of each Petri dish. The radial mycelial growth was measured at 3, 6 and 9 days after inoculation. For each treatment, three replicates were performed. The assay ended when the negative control reached full growth. The antifungal activity of the extract was calculated in terms of inhibition percentage of mycelial growth by using the following formula:

$$
\text { Inhibition }(\%)=\frac{d c-d t}{d c} \times 100,
$$

where $d c$ is the average increase in mycelia growth in negative control and $d t$ is the average increase in mycelia growth in treated sets.

\section{Results}

Visual inspection of the Petri dishes for the antifungal activity against P. cinnamomi, clearly suggests remarkable concentration-dependent growth inhibition that can be perceived by the decrease of the diameter of the colony and also by the lower density of mycelium (Figure 2). 


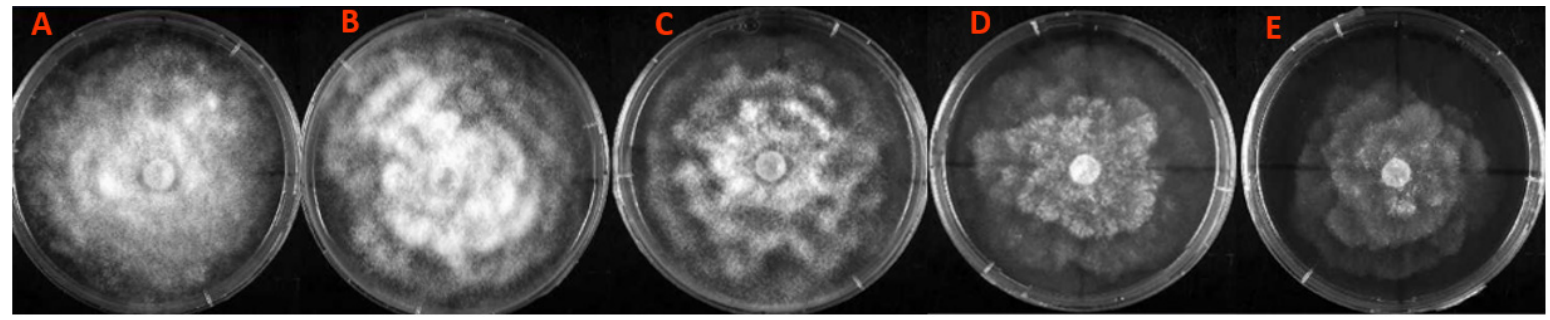

Figure 2. Representative images of P. major antifungal activity at different concentrations, 100, 500, 1000 or $2000 \mu \mathrm{g} / \mathrm{mL}$, against Phytophthora cinnamomi, on PDA solid medium, after 6 days of incubation $(\mathrm{n}=3)$. Negative control (A), $100 \mu \mathrm{g} / \mathrm{mL}$ (B), $500 \mu \mathrm{g} / \mathrm{mL}(\mathbf{C}), 1000 \mu \mathrm{g} / \mathrm{mL}$ (D) and $2000 \mu \mathrm{g} / \mathrm{mL}$ (E).

The extract inhibited growth of all fungi (Figure 3) although in some cases significance of the difference has ceased from the sixth to the ninth day incubation ( $P$. cinnamomi and D. corticola; Figure 3A and Figure 3B, respectively). These results suggest that the fungi might have adapted to the toxicity of the extract. Clear time-dependent effect with C. gloeosporioides on the third and sixth days incubation (Figure 3C) and dose-dependent effect between $100 \mu \mathrm{g} / \mathrm{mL}$ and $2000 \mu \mathrm{g} / \mathrm{mL}$ with C. acutatum (Figure 3D), C. nymphaeae (Figure $3 \mathrm{E}$ ) and $C$. godetiae (Figure $3 \mathrm{~F}$ ) were observed. The maximum growth inhibition (32.2\%) was obtained against P. cinnamomi with $2000 \mu \mathrm{g} / \mathrm{mL}$ extract (Figure 3A) followed by C. gloeosporioides ( $25.7 \%$; Figure $3 C)$ on the sixth day and by C. nymphaeae and C. godetiae (21.1\%; Figure 3E and Figure 3F, respectively) on the ninth day. 


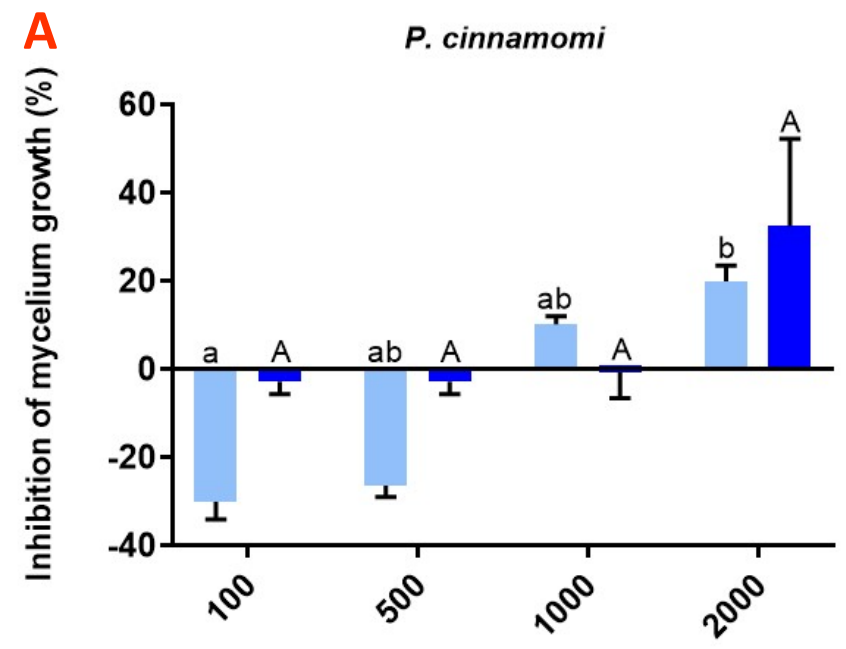

Concentration of Plantago major extract $(\mu \mathrm{g} / \mathrm{mL})$

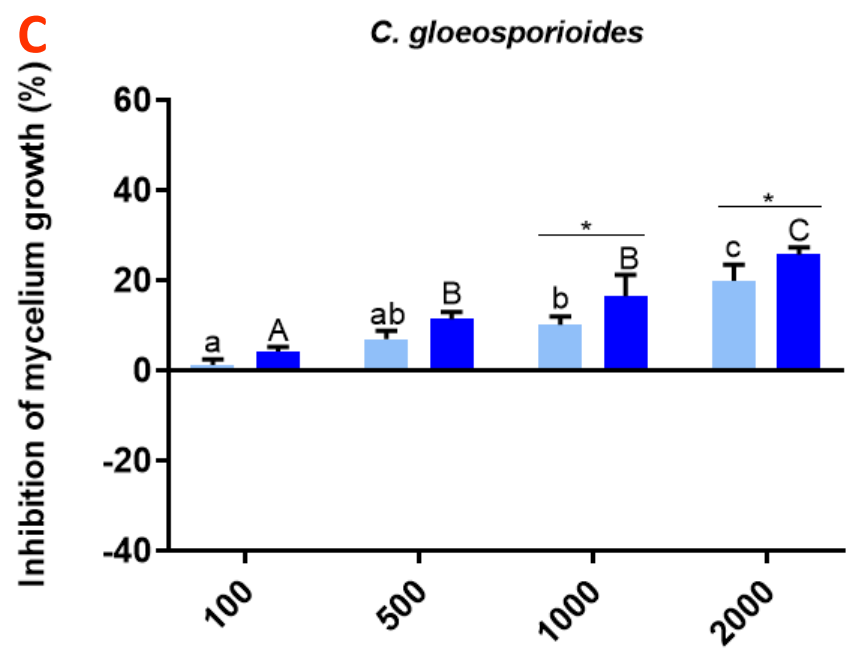

Concentration of Plantago major extract $(\mu \mathrm{g} / \mathrm{mL})$
B D. corticola

Day 3

Day 6

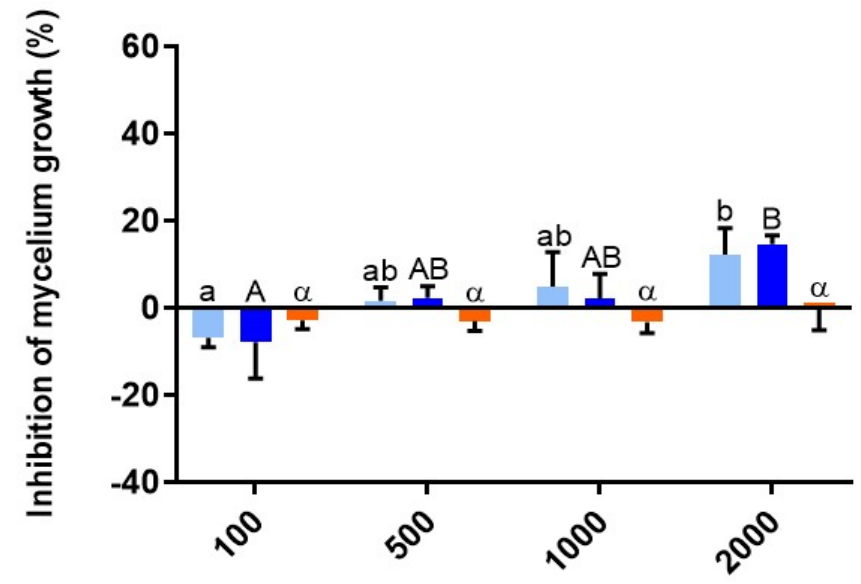

Concentration of Plantago major extract $(\mu \mathrm{g} / \mathrm{mL})$

Day 3

- Day 6

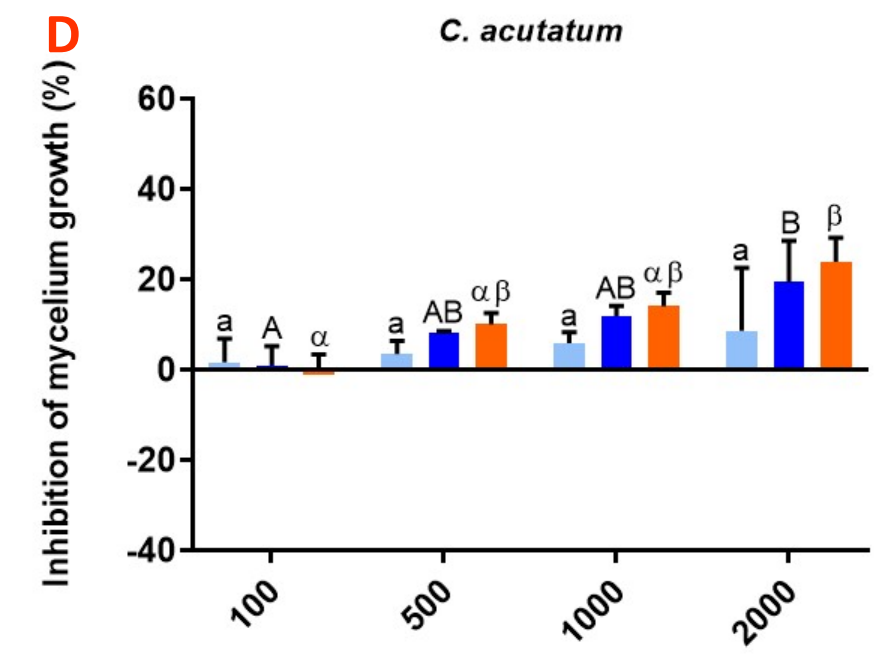

Concentration of Plantago major extract $(\mu \mathrm{g} / \mathrm{mL})$
Day 3

- Day 6

Day 9 

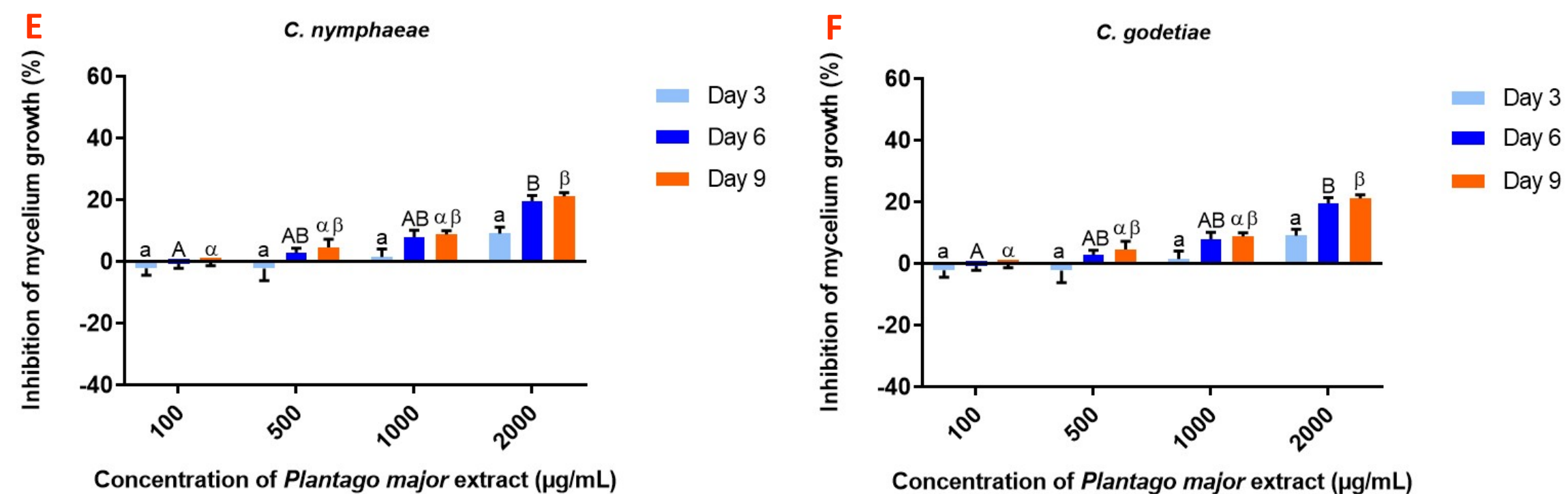

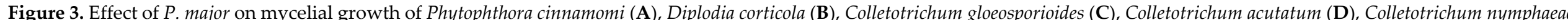

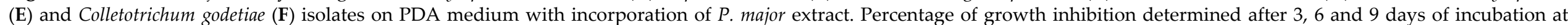

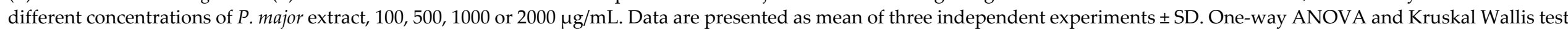

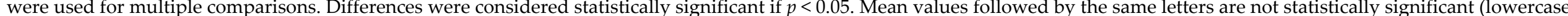

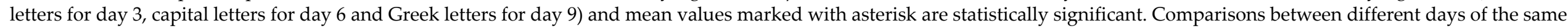
concentration are only represented if they are significant. 


\section{Conclusions}

The extract from P. major has the potential to replace synthetic fungicides with convenient application programs in crops in order to control and prevent fungal growth. By inhibiting fungal growth by $20-32.2 \%$, P. major extract would not be likely to promote fungal resistances and would not have an impact on the environment.

Institutional Review Board Statement: Not applicable.

Informed Consent Statement: Not applicable.

Data Availability Statement: The data presented in this study are available on request from the corresponding author. The data are not publicly available due to the processing delay upon submission to a public repository.

\section{References}

1. Frank, R.; Braun, H.E.; Ripley, B.D. Residues of insecticides and fungicides on Ontario-grown vegetables, 1986-1988. Food Addit. Contam. 1990, 7, 545-554, doi:10.1080/02652039009373917.

2. Wang, P.; Yang, M.; Jiang, L.; Wu, Y.J. A fungicide miconazole ameliorates tri-o-cresyl phosphate-induced demyelination through inhibition of ErbB/Akt pathway. Neuropharmacology 2019, 148, 31-39, doi:10.1016/j.neuropharm.2018.12.015.

3. Sukul, P. Enzymatic activities and microbial biomass in soil as influenced by metalaxyl residues. Soil Biol. Biochem. 2006, 38, 320-326, doi:10.1016/j.soilbio.2005.05.009.

4. Wightwick, A.; Walters, R.; Allinson, G.; Reichman, S.; Menzies, N. Environmental Risks of Fungicides Used in Horticultural Production Systems. In Fungicides; IntechOpen: London, UK, 2010, doi:10.5772/13032.

5. Lucas, J.A.; Hawkins, N.J.; Fraaije, B.A. The Evolution of Fungicide resistance. In Advances in Applied Microbiology; Elsevier: Amsterdam, The Netherlands, 2015; Volume 90, ISBN 9780128022757. 